\title{
A Stator-Separated Axial Flux-Switching Hybrid Excitation Synchronous Machine
}

\author{
Xiping Liu*, Aihua Zheng* and Chen Wang*
}

\begin{abstract}
In this paper, a stator-separated axial flux-switching hybrid excitation synchronous machine (SSAFHESM) is presented, of which the structure and operational principle are introduced. The magnetic field distribution under different excited currents is analyzed, and some characteristics including flux-linkage, EMF and field control ability are studied by finite element analysis (FEA). Tests are carried out on a 12/10-pole prototype machine to validate the analysis results, and an excellent agreement is obtained.
\end{abstract}

Keywords: Axial field, Flux-switching, Hybrid excitation, Stator-separated, Finite element analysis.

\section{Introduction}

A flux-switching hybrid excitation synchronous machine (FSHESM) was proposed in 2007 [1]. It has better qualities compared to the flux-switching PM synchronous machine, as the air-gap field can be adjusted due to the field windings[2], [3]. Therefore, this type of machine has been extensively investigated in recent years [4]-[8]. However, the previous researches on the FSHESM are focused on the radial magnetic field machine, which has some inherent defects such as low core utilization rate, a bottleneck effect in the tooth root and so on.

Incorporating the advantageous features of the axial magnetic field and the flux-switching hybrid excitation machine, a stator-separated axial flux-switching hybrid excitation synchronous machine (SSAFHESM) is proposed, of which the structure and operation principle are introduced and some electromagnetic characteristics are studied by FEA. Furthermore, a three-phase 12/10-pole prototype machine is built and some tests are carried out, which verify the FEA results.

\section{Structure and Operational Principle}

\subsection{Structure}

Fig. 1 shows the structure of a three-phase 12/10-pole SSAFHESM which is composed of a back-to-back stator and two disc rotors. The rotors are connected with the stator

\footnotetext{
* Dept. of Electrical Engineering and Automation, Jiangxi University of Science and Technology, China.(1iuxp211@163.com, 493620236.qq.com, binggu98@126.com).

Received 10 March 2012; Accepted 26 July 2012
}

coaxially. The outspread drawing of the half stator is shown in Fig.2. Several " $H$ " type stator cores assemblies form the whole stator core of the SSAFHESM, which is divided into two independent parts by the non-magnetizer. A concentrated coil is wound around the two adjacent teeth with one PM and one field bracket in the middle, the magnetization being reversed in polarity from one PM to the next. The field windings are axially wound on the surface of the field brackets, which makes it appear to be a brushless AC machine. The magnetic field in the machine is distributed axially, which is conductive to heat dissipation, lowering the heat loss and improving the efficiency of the machine. The major design dimensions of the machine are listed in Table 1.

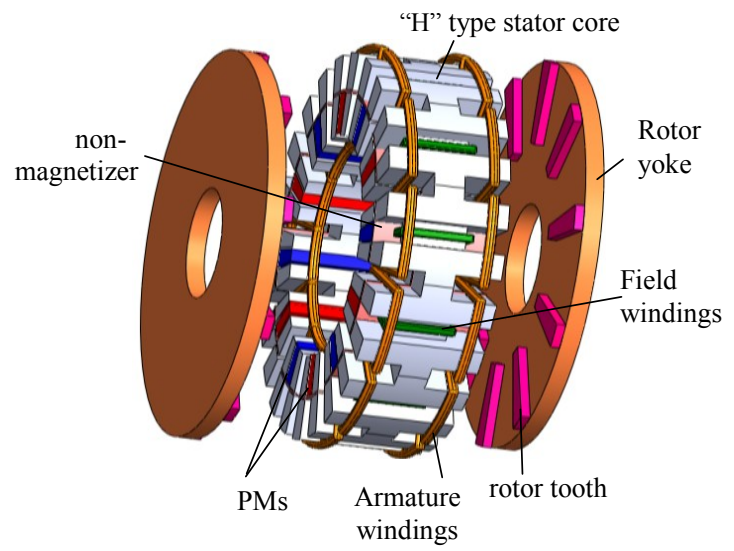

Fig.1. Structure of the 12/10-pole SSAFHESM.

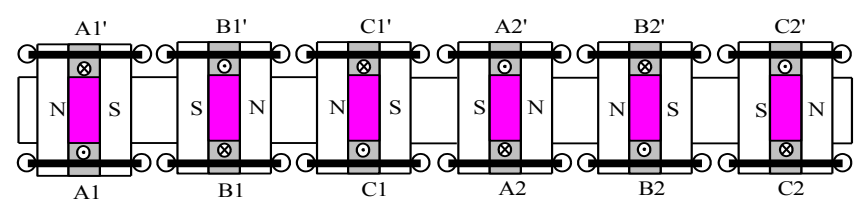

Fig.2. Outspread drawing of the stator. 


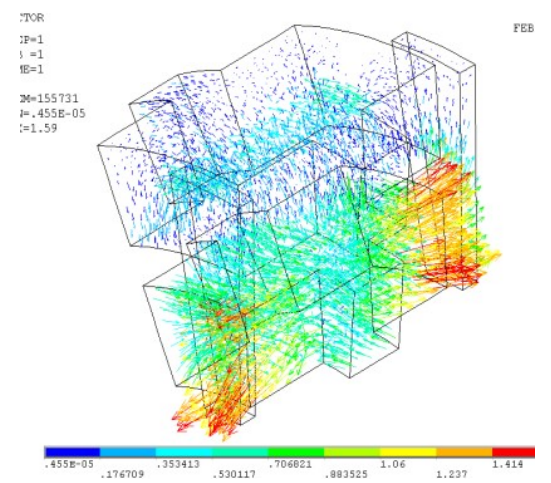

(a)

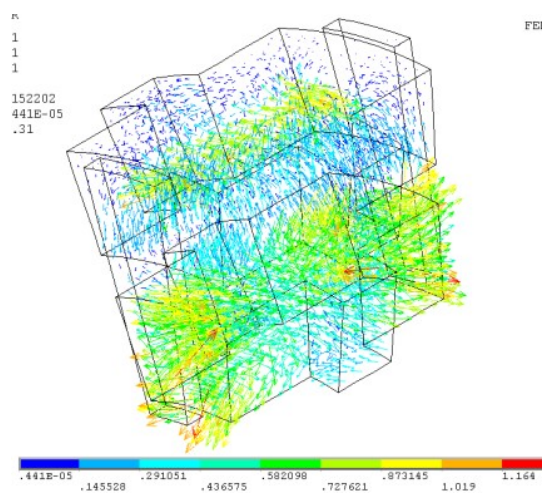

(b)

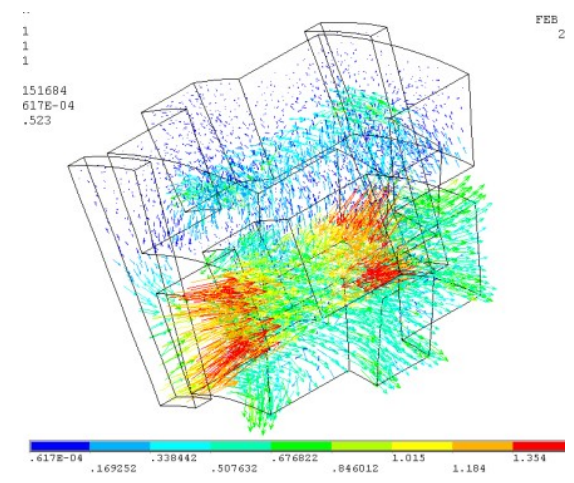

(c)

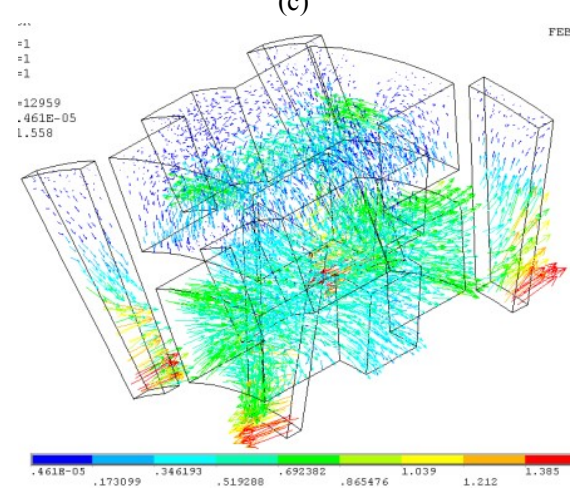

(d)

In addition, as the stator core is divided into inner and outer parts by the non-magnetizer, the DC field magnetic circuit and PM magnetic circuit are independent of each other, which can avoid the demagnetization of the PMs.

Table 1. Major Design Dimensions of SSAFHESM

\begin{tabular}{cc}
\hline \hline Items & Values \\
\hline Number of phase & 3 \\
Rated speed (r/min) & 400 \\
Stator slot number & 12 \\
Rotor pole number & 10 \\
Stator outer diameter (mm) & 152 \\
Stator inner diameter (mm) & 80 \\
Depth of the non- & 6 \\
magnetizer(mm) & 15 \\
Depth of the magnet (mm) & 1 \\
Air-gap length (mm) & 7.5 \\
Stator magnet arc (deg.) & 7.5 \\
Stator tooth arc (deg.) & 7.5 \\
Stator slot arc (deg.) & 10.5 \\
Rotor pole arc (deg.) & \\
\hline \hline
\end{tabular}

\subsection{Operation Principle}

The open-circuit flux distributions under the PM exc itation alone are investigated by FEA. There are four $t$ ypical rotor positions, as shown in Fig.3, where $\theta$ repr esents the rotor position. Define $\theta=0^{\circ}$ when the rotor is aligned with one of two stator teeth over which a coil is wound, as shown in Fig.3 (a). As can be seen from Fig.3 (a) and Fig.3 (c), the rotor pole is aligned with the stator tooth, and therefore the flux-linkage of armature coils reaches the positive and negative maxim um, respectively. Between the positive and negative flu $\mathrm{x}$-linkages, zero flux-linkage occurs whenever the rotor pole is aligned with the PM (Fig.3 (b)) or the stator slot (Fig.3 (d)). Thus, the polarities of the phase flux-1 inkage are switched and alternating EMF is induced ac cording to the rotor positions, as shown in Fig.4.

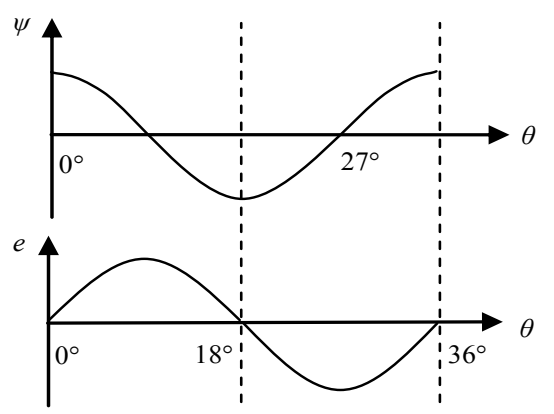

Fig.4. Ideal phase flux-linkage and EMF.

\section{FEA Model and Results}

Fig.3. Open-circuit flux distributions. (a) $\theta=0^{\circ}$. (b) $\theta=9^{\circ}$.
(c) $\theta=18^{\circ}$
(d) $\theta=27^{\circ}$.

\subsection{FEA Model}

As there are axial and radial magnetic flux distributions 
in an SSAFHESM, it is difficult for the traditional method of equivalent magnetic circuit to calculate the magnetic field distribution accurately. A 3-D FEA structural model of the machine is built in Fig.5 (a), and the FEA mesh model with 223978 nodes and 160031 elements is shown in Fig.5 (b).

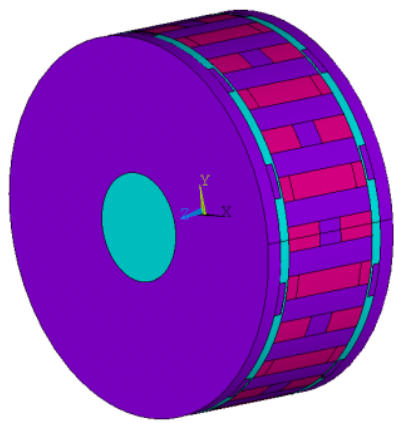

(a)

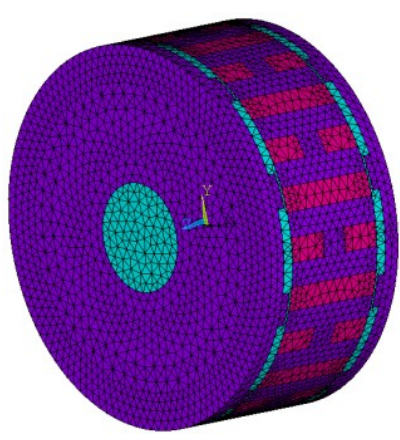

(b)

Fig.5. FEA model of SSAFHESM. (a) Structural model.

(b) Mesh model.

\subsection{Air-gap Flux Density}

Neglecting the saturation and armature effects and using the principle of flux superposition, the resultant air-gap flux can be defined as

$$
\phi_{g}=\phi_{P M}+\phi_{D C}
$$

where $\phi_{g}$ is the resultant air-gap flux, $\phi_{P M}$ is flux produced by the PMs, $\phi_{D C}$ is flux produced by the DC field current. As the PM flux is constant, the air-gap flux can be enhanced or weakened according to the field current.

The 3-D axial air-gap flux density distribution waveforms are shown in Fig.6 for three different cases of the DC field current (0 Aturns, +600 Aturns and -600 Aturns). The air-gap flux density is enhanced when the direction of the flux density due to field current is consistent with that of the PM flux density (Fig.6 (b)). Similarly, the air-gap flux density is weakened when the direction of the flux density due to field current is opposite to that of the PM flux density (Fig.6 (c)). The slotting effects of the machine are also obvious from the plots.

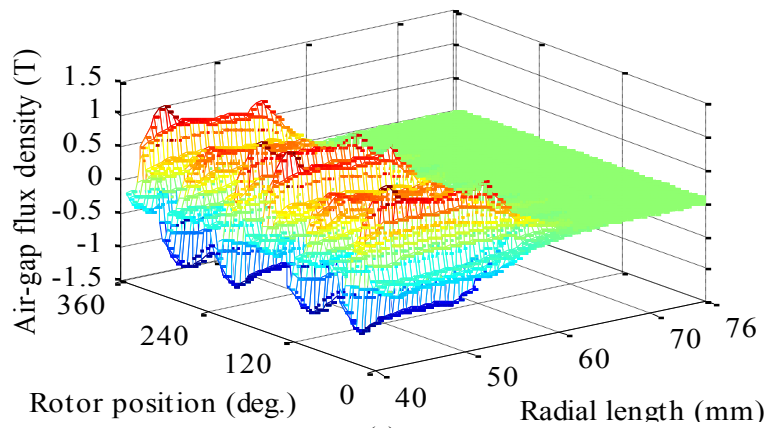

(a)

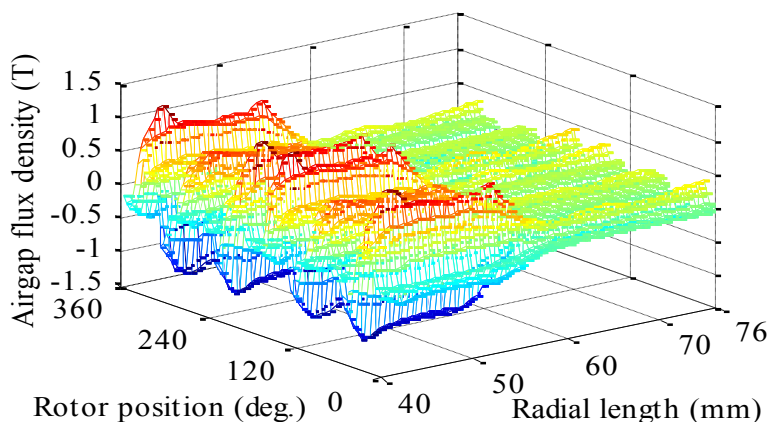

(b)

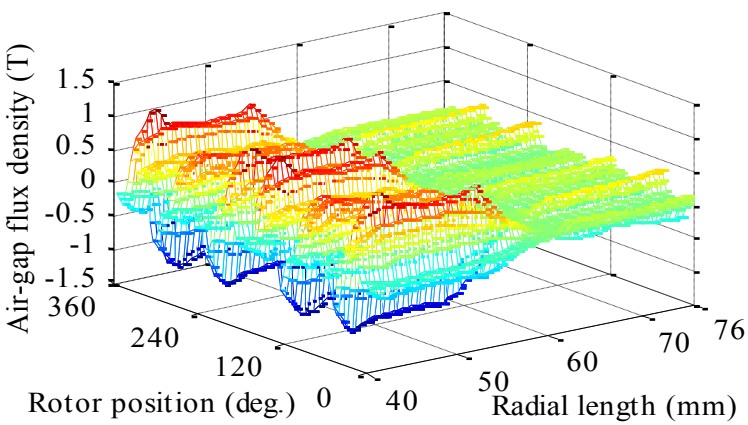

(c)

Fig.6. 3-D axial air-gap flux density distributions.

(a)0 Aturns. (b)+600 Aturns. (c)-600 Aturns.

The PM and the armature axial air-gap flux density distributions are compared in Fig.7. Obviously, the axial air-gap flux is mostly produced by the PMs.

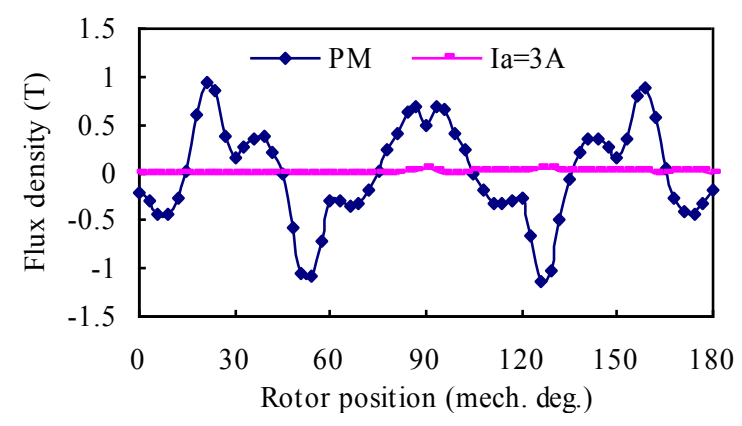

Fig.7. 2-D axial air-gap flux density. 


\subsection{PM Flux-linkage and EMF}

The coils and resultant phase PM flux per turn are shown in Fig.8 (a), which shows that the resultant phase flux direction on one side of the stator is reverse to that on the other side of the stator. The phase flux can be obtained by

$$
\phi_{A}=\phi_{A 1}+\phi_{A 2}+\phi_{A 3}+\phi_{A 4}-\left(\phi_{A 1}{ }^{\prime}+\phi_{A 2}{ }^{\prime}+\phi_{A 3}{ }^{\prime}+\phi_{A 4}{ }^{\prime}\right)
$$

where $\phi_{\mathrm{A}}$ represents the flux of phase $\mathrm{A}, \phi_{A 1} \sim \phi_{A 4}$ represent the flux of coil A1 A4 on one side of the stator, $\phi_{A 1}{ }^{\prime} \sim \phi_{A 4}{ }^{\prime}$ represent the flux of coil A1' $\sim \mathrm{A} 4$ ' on the other side of the stator.

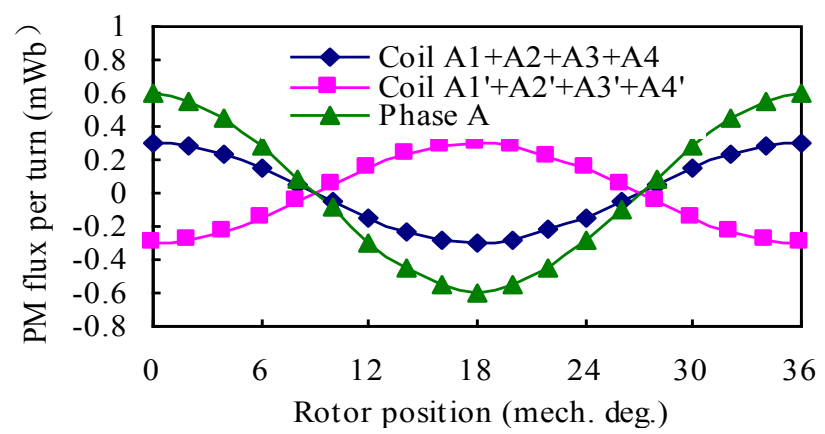

(a)

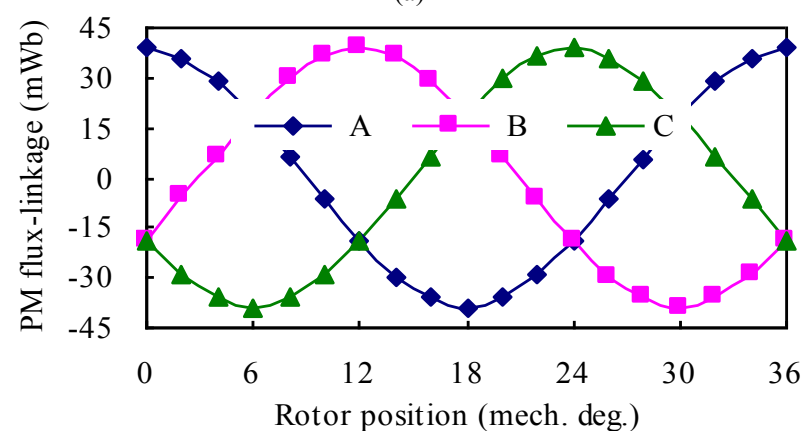

(b)

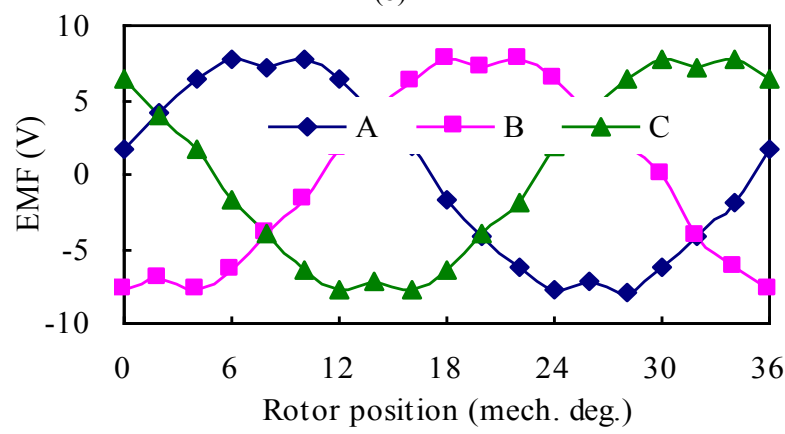

(c)

Fig.8. Static characteristics at no-load. (a) Coils and phase PM fluxes excited by the PMs. (b) 3-phase PM flux-linkage. (c) 3-phase EMF.

The EMF of the SSAFHESM is calculated according to the change of the phase windings flux-linkage by

$$
e=-\frac{d \psi}{d t}=-N \frac{d \phi}{d \theta} \frac{d \theta}{d t}=-N \omega \frac{d \phi}{d \theta}
$$

where $N$ is the winding turns per phase, $\omega$ is the an gular speed of the rotor, $\psi$ and $\phi$ are the flux-linkage a nd flux of the phase windings, respectively. Fig.8 (b) $\mathrm{s}$ hows three-phase magnetic flux-linkage waveforms of $t$ he armature windings for one period excited by the $\mathrm{P}$ $\mathrm{M}$ only. Correspondently, the induced three-phase EMF $\mathrm{s}$ at $400 \mathrm{rpm}$ are shown in Fig.8 (c), which shows the phase-shifts between the three waveforms are balanced strictly.

\subsection{Field Control Ability}

The field control ability of the SSAFHESM is shown in Fig.9. The phase fluxes under different field currents are compared in Fig.9 (a). Obviously, the flux linked in the phase armature windings can be enhanced or weakened according to the field currents. Correspondingly, the phase EMF can be controlled evidently by regulating the field currents, as shown in Fig.9 (b). The effects of flux enhancing and weakening are almost the same because the DC field magnetic circuit and PM magnetic circuit are independent of each other.

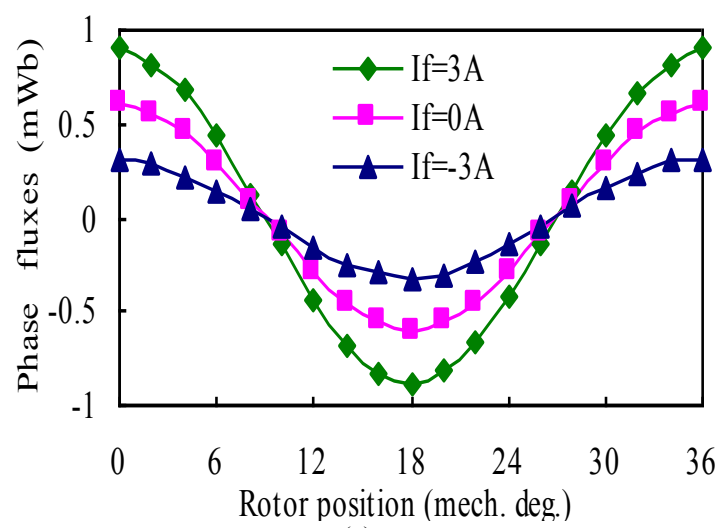

(a)

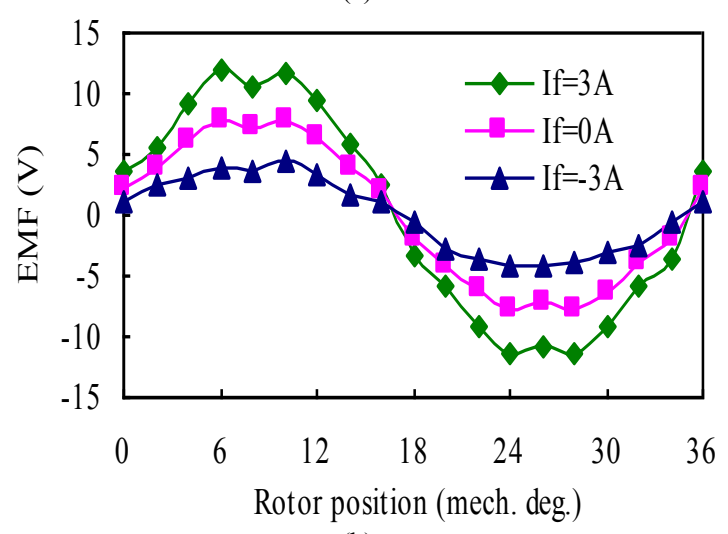

(b)

Fig.9. Field control ability. (a) Phase fluxes. (b) Phase EMFs. 


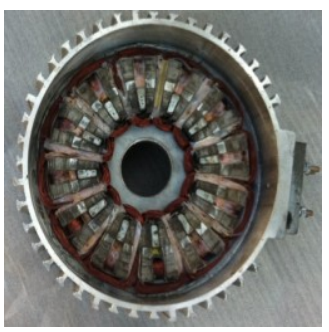

(a)

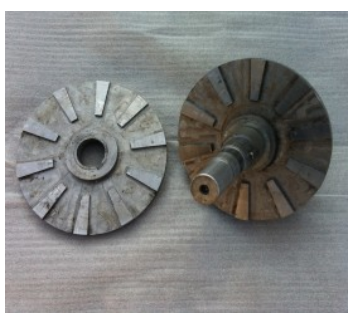

(b)
Fig.10. Prototype of the SSAFHESM. (a) Stator. (b) Rotor.

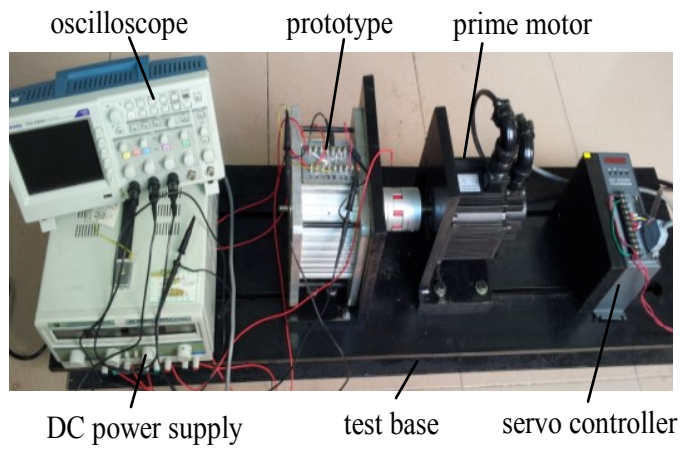

Fig.11.Test platform for SSAFHESM.
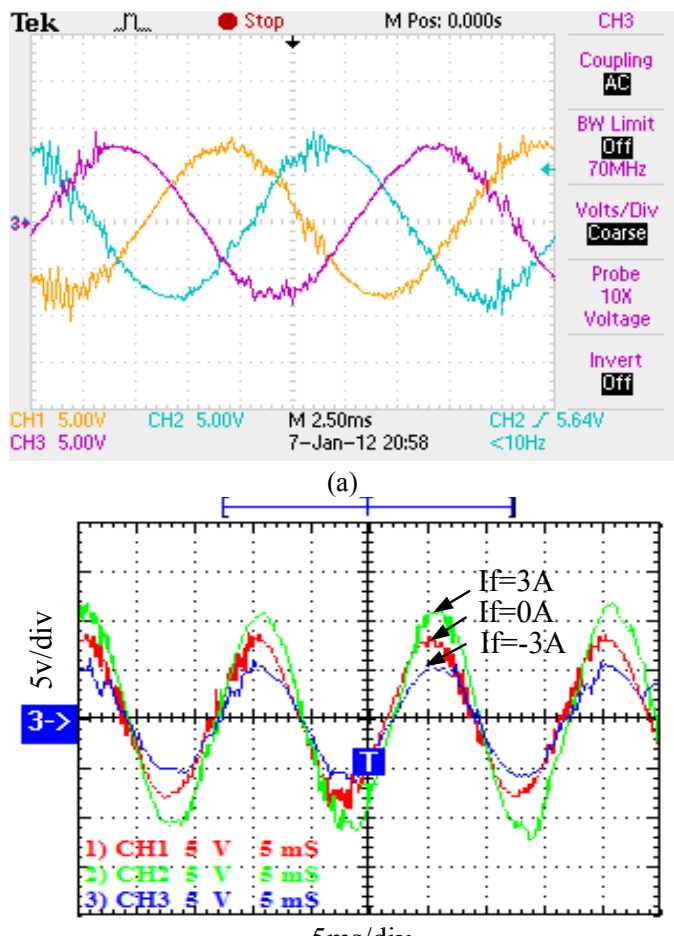

(b)

Fig.12. Measured results. (a) 3-phase EMF. (b) Phase EMF under different field currents.

\section{Test Results}

Based on the given parameters in Table I, a prototype of the 12/10-pole SSAFHESM is manufactured, as shown in Fig.10. The platform for experimental investigations on the prototype is shown in Fig.11. The prototype is connected with the prime motor by a coupling. The prime motor, a PM synchronous machine, provides torque and speed for the prototype, and it is controlled by the servo controller. The DC power supply offers a DC current for the field windings.

The measured no-load waveforms of three-phase EMF and phase EMF under different field currents are shown in Fig.12 (a) and Fig.12 (b), which agree well with the FEA predicted results shown in Fig.8 (c) and Fig.9 (b), respectively.

\section{Conclusion}

A stator-separated axial flux-switching hybrid excitation machine is proposed in this paper. The magnetic flux distributions, flux-linkage and EMF of the phase windings are computed by a 3-D finite element method. A prototype machine is manufactured and some tests are carried out. The FEA and test results show that the developed 12/10pole SSAFHESM has a good capability of field control.

\section{Acknowledgements}

This work was supported by the National Natural Science Foundation of P. R. China (No.51007033, 51267006), the Science Foundation of Jiangxi Province of P. R. China (20122BAB206031), and the Plan Project of Jiangxi Province of P. R. China (GJJ09517).

\section{References}

[1]E. Hoang, M. Lecrivain, and M. Gabsi, "A New Structure of a Switching Flux Synchronous Polyphased Machine with Hybrid Excitation," in 12th Eur. Conf. Power Electron. Appl., Sep. 2007, pp. 1-8.

[2] Y. Chen, Z. Q. Zhu, and D. Howe, "Three-Dimensional Lumped-Parameter Magnetic Circuit Analysis of SinglePhase Flux-Switching Permanent-Magnet Motor," IEEE Trans. Ind. Appl., vol. 44, no. 6, pp. 1701-1710, Nov./Dec. 2008.

[3]Z. Q. Zhu, J. T. Chen, and D. Howe, "Analysis of a Novel Multi-Tooth Flux-Switching PM Brushless Ac Machine for High Torque Direct-drive Applications," IEEE Trans. Magn., vol. 44, no. 11, pp. 4313-4316, 2008.

[4] W. Hua, M. Cheng, and G. Zhang. "A Novel Hybrid Excitation Flux-Switching Motor for Hybrid Vehicles," IEEE Trans. Magn., vol. 45, no. 10, pp. 4728-4731, Oct. 2009.

[5] R. L. Owen, Z. Q. Zhu, and G. W. Jewell, "Hybrid Excited Flux-Switching Permanent Magnet Machines with Iron Flux Bridges," IEEE Trans. Magn., vol. 46, no. 6, pp. 1726-1729, Jun. 2010. 
[6] E. Sulaiman, Y. Tsujimori, T. Kosaka, and N. Matsui, "Design of 12-slot 10-Pole Permanent Magnet Flux Switching Machine with Hybrid Excitation for Hybrid Electric Vehicle," in Proc.5th IET Int. Conf. Power Electron. Mach. Drives, Apr., 2010, pp. 1-5.

[7] E. Hoang, S. Hlioui, M. Lecrivain, and M. Gabsi, "Experimental Comparison of Lamination Material Case Switching Flux Synchronous Machine with Hybrid Excitation," in Proc. 13th Eur. Conf. Power Electron. Appl., Sep. 2009, pp. 1-7.

[8] E. Sulaiman, T. Kosaka, and N. Matsui, "A Novel Hybrid Excitation Flux Switching Synchronous Machine for a HighSpeed Hybrid Electric Vehicle Applications," in Proc. Int. Conf. Elec. Mach. Syst., Aug. 2011, pp. 1-6.

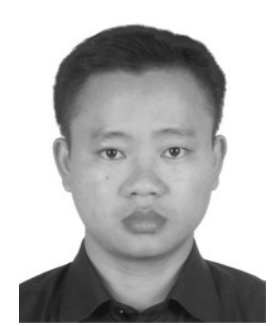

Xiping Liu received his B.S. degree from Hohai University, Nanjing, China, in 1999, and his M.S. degree from Jiangxi University of Science and Technology, Ganzhou, China, in 2004, and his Ph.D. degree in electrical engineering from Southeast University, Nanjing, China, in 2009. In 1999, he joined the School of Mechanical and Electrical Engineering, Jiangxi University of Science and Technology as a lecturer. Currently, he is an associate professor in the department of Electrical Engineering and Automation. His major research interests include the analysis and design of permanent magnet synchronous machines, wind power technology.

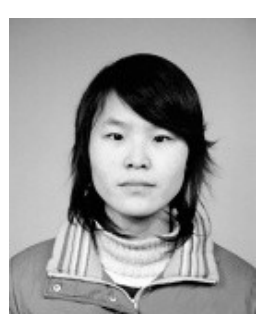

Aihua Zheng received her B.S. degree from Pingdingshan University, Pingdingshan, China, in 2010. She is currently a postgraduate student in the department of Electrical Engineering and Automation, Jiangxi University of Science and Technology. Her major research interests include the design and analysis of permanent magnet synchronous machines.

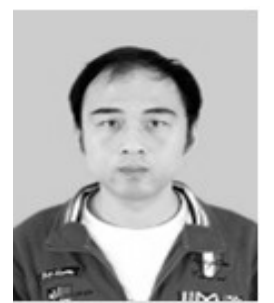

Chen Wang received his B.S. degree from Xidian University, Xi'an, China, in 2010 . He is currently a postgraduate student in the department of Electrical Engineering and Automation, Jiangxi University of Science and Technology. His major research interests include the design and analysis of permanent magnet synchronous machines. 